\title{
Calcium-binding calmyrin forms stable covalent dimers in vitro, but in vivo is found in monomeric form ${ }^{\star \star}$
}

\author{
Adam Sobczak ${ }^{1}$, Magdalena Blazejczyk ${ }^{1}$, Grzegorz Piszczek², Gang Zhao ${ }^{1}$, Jacek \\ Kuznicki $^{1,3}$ and Urszula Wojda ${ }^{1 凶}$ \\ ${ }^{1}$ Laboratory of Neurodegeneration, International Institute of Molecular and Cell Biology, Warsaw, Poland; \\ ${ }^{2}$ Laboratory of Biochemistry, NHLBI/NIH, Bethesda, MD 20892-8012, USA; ${ }^{3}$ Nencki Institute of Experimental \\ Biology, Laboratory of Calcium-Binding Proteins, Warsaw, Poland; ${ }^{\circledR e-m a i l: ~ u l a w o j d a @ i i m c b . g o v . p l ~}$
}

Received: 10 February, 2005; revised: 25 February, 2005; accepted: 19 April, 2005 available on line: 01 June, 2005

\begin{abstract}
The EF-hand $\mathrm{Ca}^{2+}$-binding protein calmyrin is expressed in many tissues and can interact with multiple effector proteins, probably as a sensor transferring $\mathrm{Ca}^{2+}$ signals. As oligomerization may represent one of $\mathrm{Ca}^{2+}$-signal transduction mechanisms, we characterised recombinant calmyrin forms using non-reducing SDS/PAGE, analytical ultracentrifugation and gel filtration. We also aimed at identification of biologically active calmyrin forms. Non-reducing SDS/PAGE showed that in vitro apo- and $\mathrm{Ca}^{2+}$-bound calmyrin oligomerizes forming stable intermolecular disulfide bridges. Ultracentrifugation indicated that at a $220 \mu \mathrm{M}$ initial protein concentration apo-calmyrin existed in an equilibrium of a $21.9 \mathrm{kDa}$ monomer and a $43.8 \mathrm{kDa}$ dimer (trimeric or tetrameric species were not detected). The dimerization constant was calculated as $K_{\mathrm{a}}=1.78 \times 10^{3} \mathrm{M}^{-1}$ at $6^{\circ} \mathrm{C}$. Gel filtration of apo- and $\mathrm{Ca}^{2+}$-bound calmyrin at a $100 \mu \mathrm{M}$ protein concentration confirmed an equilibrium of a monomer and a covalent dimer state. Importantly, both monomer and dimer underwent significant conformational changes in response to binding of $\mathrm{Ca}^{2+}$. However, when calmyrin forms were analyzed under non-reducing conditions in cell extracts by Western blotting, only monomeric calmyrin was detected in human platelets and lymphocytes, and in rat brain. Moreover, in contrast to recombinant calmyrin, crosslinking did not preserve any dimeric species of calmyrin regardless of $\mathrm{Ca}^{2+}$ concentrations. In summary, our data indicate that although calmyrin forms stable covalent dimers in vitro, it most probably functions as a monomer in vivo.
\end{abstract}

Keywords: EF-hand calcium-binding proteins, calmyrin monomer, covalent dimer, human lymphocytes

$\mathrm{Ca}^{2+}$ signals play a pivotal role in the regulation of many fundamental cellular processes ranging from rapid modulations of effector proteins to changes in gene expression (Berridge, 1998). The precise transduction of $\mathrm{Ca}^{2+}$ signals is mediated by a multitude of $\mathrm{Ca}^{2+}$-binding proteins $(\mathrm{CaBP})$, of which numerous belong to the EF-hand superfamily (Heizmann \& Hunziker, 1991; Nakayama \& Kretsinger, 1994). These proteins are characterized by the presence of EF-hand motifs where $\mathrm{Ca}^{2+}$ is bound at increasing cellular $\mathrm{Ca}^{2+}$ concentrations, what in turn changes their conformation and triggers interactions with cellular targets, resulting in modulation of enzymes, ion channels or cell surface receptors (Ikura, 1996).
Calmyrin, also termed CIB (Naik et al., 1997) or KIP (Wu \& Lieber, 1997), contains four EF-hand motives, two of which, located in the C-terminal half of the protein, are canonical and have been shown to bind $\mathrm{Ca}^{2+}$ with high affinities (Yamniuk et al., 2004; Gentry et al., 2004). Calmyrin aminoacid sequence shows highest similarity to calcineurin $\mathrm{B}$ and calmodulin ( $58 \%$ and $56 \%$, respectively), two typical ubiquitous EF-hand $\mathrm{Ca}^{2+}$-sensor proteins (Naik et al., 1997). In addition, the structural features of calmyrin are similar to the group of EF-hand neuronal calcium sensor (NCS) proteins known also as recoverin family (Burgoyne \& Weiss, 2001). In accord with structural similarities to the NCS proteins, we have recently described in details

*Paper dedicated to the memory of Professor Witold Drabikowski and Professor Gabriela Sarzała-Drabikowska.

$\star$ Part of the results were presented at the 40th FEBS Meeting in Warsaw, Poland, 2004.

Abbreviations: BS3, bis-(sulfosuccinimidyl)suberate; BSA, bovine serum albumin; CaBP, $\mathrm{Ca}^{2+}$-binding proteins; DTT, dithiothreitol; KChIP, potassium channel inhibitory protein or calsenilin; 2-ME, 2-mercaptoethanol; NCS, neuronal calcium sensor; PBS, phosphate buffered saline; TCEP, Tris[2-carboxyethyl]phosphine. 
calmyrin expression in certain areas of human brain (Berstein et al., 2005). However, in contrast to the NCS proteins, calmyrin expression is not limited to neurons, but has been found in a variety of human tissues (Naik et al., 1997; Wu et al., 1997, Stabler et al., 1999; Kauselmann et al., 1999). This broad expression pattern suggests an involvement of calmyrin in a variety of cellular functions, and indeed calmyrin has been shown to interact with a broad spectrum of proteins that are involved in diverse cellular processes. The list of calmyrin targets includes integrin alpha IIb (Naik et al., 1997), the polo-like kinases Snk/Fnk (Kauselmann et al., 1999; Ma et al., 2003), a protein coded by the gene NBR1 located next to BRCA1 (Whitehouse, 2002), DNA-dependent protein kinase (Wu \& Lieber, 1997), ubiquitin-protein ligase EDD (Henderson et al., 2002), human telomerase reverse transcriptase (Lee et al., 2004), coagulation factor VIII (Fang et al., 2001), caspase-2s (Ito et al., 2000), Pax3 (Hollenbach et al., 2002), focal adhesion kinase (Naik \& Naik, 2003) and presenilin 2 (Stabler et al., 1999). The mechanisms used by this one protein to transmit $\mathrm{Ca}^{2+}$ signals to such a variety of target molecules remain to be elucidated.

One of the possible $\mathrm{Ca}^{2+}$-induced mechanisms of target recognition and binding involves exposition of hydrophobic pockets in an EF-hand protein that bind $\alpha$-helices of a protein ligand. Such pockets have been described in the crystal structure of calmyrin molecule in an area located on the opposite side from the functional $\mathrm{Ca}^{2+}$-binding EF-hands 3 and 4 (Gentry et al., 2004). A second type of $\mathrm{Ca}^{2+}$ signalling was described as a $\mathrm{Ca}^{2+}$-myristoyl switch for some myristoylated NCS proteins (Meyer \& York, 1999). As shown for recoverin (Ames et al., 1997), $\mathrm{Ca}^{2+}$-binding causes extrusion of an N-terminal myristoyl group from a hydrophobic cavity in the protein molecule, providing a mechanism of anchoring $\mathrm{Ca}^{2+}$-binding proteins to intracellular and plasma membranes in response to elevated $\mathrm{Ca}^{2+}$ levels. Calmyrin has been shown to be myristoylated at its $\mathrm{N}$-terminus (Stabler et al., 1999), but so far no $\mathrm{Ca}^{2+}$ dependent translocation to intracellular membranes has been demonstrated. A third mechanism of $\mathrm{Ca}^{2+}$ signalling seems related to protein oligomerization, but no simple common paradigm exists. $\mathrm{Ca}^{2+}$-binding regulates oligomerization of some calmyrin homologs from the NCS protein family. Neurocalcin forms a dimer upon $\mathrm{Ca}^{2+}$-binding (Vijay-Kumar \& Kumar, 1999), while its $\mathrm{Ca}^{2+}$-free form is monomeric (Olshevskaya et al., 1999). An opposite way of $\mathrm{Ca}^{2+}$-dependent dimerization was described for guanylate cyclase-activating protein 2, which forms dimers only in its apo-form (Olshevskaya et al., 1999). An involvement of other factors in $\mathrm{Ca}^{2+}$-dependent dimerization has also been shown for some NCS proteins. Potassium channel inhibitory protein 3 (KChIP3, also known as calsenilin) in its $\mathrm{Ca}^{2+}$-free state exists as a tetramer, while $\mathrm{Ca}^{2+}$-bound calsenilin is dimeric, but only at low protein concentrations (Osawa et al., 2001). KChIP1 dimerization occurs in the presence of its ligand (Zhou et al., 2004). Recently Gentry et al. (2004) described the crystal structure of calmyrin obtained at $2.0 \AA$ resolution. The asymmetric crystal unit contained two calmyrin molecules. The authors showed however, that in vitro calmyrin was largerly monomeric, as evidenced by analytical ultracentrifugation and gel filtration over a dynamic range of concentrations, in the presence or absence of $\mathrm{Ca}^{2+}$. Nevertheless, the experimental conditions used did not allow addressing the calmyrin's ability to form covalent, disulfide-bound oligomers; such a possibility is demonstrated in the present study. As one of the mechanisms of $\mathrm{Ca}^{2+}$ signalling and differential target recognition may involve formation of various quaternary protein structures in the cell, we also attempted detecting the calmyrin forms in cell extracts.

\section{MATERIALS AND METHODS}

Purification of recombinant calmyrin and analysis of protein disulfide bridges by non-reducing SDS/PAGE. Recombinant calmyrin was obtained as described previously (Bernstein et al., 2005). Briefly, a full length human calmyrin cDNA (GenBank accession No. U82226.1) was obtained by RT-PCR using human lymphocyte mRNA as the starting material. The amplification product was cloned into bacterial pET28a vector containing N-terminal Histag (Novagen) and expressed in Escherichia coli. Calmyrin was purified from bacterial lysate using $\mathrm{Ni}^{2+}$ nitriloacetic acid-agarose resin according to manufacturer's instructions (Qiagen). Protein eluted at 100 $\mathrm{mM}$ imidazole was concentrated on Amicon YM 10 membrane (Millipore), dialyzed $3 \times 2 \mathrm{~h}$ against 20 $\mathrm{mM}$ Tris/ $\mathrm{HCl}, \mathrm{pH} 7.5,100 \mathrm{mM} \mathrm{NaCl}$, and cleaved overnight with thrombin (Sigma) to remove the His-Tag. The protein was further purified by FPLC anion-exchanger chromatography on a MonoQ column connected to the Akta Purifier system (Amersham) and resin-bound calmyrin was eluted with a continuous gradient of $150-250 \mathrm{mM} \mathrm{NaCl}$. This fraction was concentrated to $18 \mathrm{mg} / \mathrm{ml}$ using Vivaspin centrifugal concentrators, cut off $10 \mathrm{kDa}$ (Sigma), and $200 \mu \mathrm{l}$ samples were applied on a gel filtration Superose 12 column (Amersham) equilibrated in 20 $\mathrm{mM}$ Tris/ $\mathrm{HCl}, \mathrm{pH} 7.5,150 \mathrm{mM} \mathrm{NaCl}$. After elution at $0.3 \mathrm{ml} / \mathrm{min}$ in this buffer, protein peaks were analyzed by non-reducing 12\% SDS/PAGE, i.e. omitting reducing agents from the sample buffer. Reduction of calmyrin disulfides was investigated using 2mercaptoethanol (2-ME), dithiothreitol (DTT), and Tris[2-carboxyethyl]phosphine (TCEP) from Pierce (Germany). The reducing agents were added to pro- 
tein samples preincubated for $30 \mathrm{~min}$ with $0.2 \mathrm{mM}$ $\mathrm{CaCl}_{2}$ or $2 \mathrm{mM}$ EGTA at a $2.5 \mathrm{mg} / \mathrm{ml}$ protein concentration. The protein samples were then subjected to non-reducing SDS/PAGE as described above.

Analytical ultracentrifugation. A Beckmam, Inc. Optima XL-I analytical ultracentrifuge equipped with a four-place An-Ti rotor was used for sedimentation equilibrium experiments at $6.0^{\circ} \mathrm{C}$. The density of the AUC buffer $(20 \mathrm{mM}$ Tris/ $\mathrm{HCl}, 150 \mathrm{mM} \mathrm{NaCl}$, $1 \mathrm{mM}$ EGTA, $2 \mathrm{mM}$ 2-ME, pH 7.5) was $1.00563 \mathrm{~g} / \mathrm{ml}$ at $20.00 \pm 0.01^{\circ} \mathrm{C}$, as determined with an Anton Paar Model DMA-58 densitometer. A partial specific volume of $0.717 \mathrm{ml} / \mathrm{g}$ was calculated for calmyrin from the amino-acid composition and the values of Zamyatnin (1984). For interference optics the calibration value of $3.191 \pm 0.005$ fringes $(\mathrm{mg} / \mathrm{ml})^{-1}$ (Nosworthy et al., 1998) was used. For sedimentation equilibrium runs, $0.110 \mathrm{ml}$ calmyrin $(4.84 \mathrm{mg} / \mathrm{ml}$ protein) dialyzed overnight against the AUC buffer was loaded into the right channel of a double sector cell $(1.2 \mathrm{~cm}$ path length) equipped with sapphire windows and a carbon-filled epoxy centerpiece, and $0.110 \mathrm{ml}$ of dialysate was placed in the reference channel. The rotor was accelerated to 3000 r.p.m. until optical calibrations and initial scans were performed and then maintained at 42000 r.p.m. for $26 \mathrm{~h}$ with interference scans made at $10 \mathrm{~min}$ intervals. The last 25 interference scans overlaped entirely and showed that the meniscus was completely cleared from the protein (meniscus depletion method). Subsequently the rotor speed was reduced to 18000 r.p.m. and maintained at that speed for $75 \mathrm{~h}$. During that time programmed absorbance autoscans at $280 \mathrm{~nm}$ (7 averages, $0.001 \mathrm{~cm}$ steps in the step-mode) were made at $2 \mathrm{~h}$ intervals. At the end of the run the protein was removed from the assembled cell and the right channel was flushed repeatedly before reloading with dialysate. Interference and absorbance baselines for subtraction from the final scans were obtained at rotor speeds of 42000 r.p.m. and 18000 r.p.m., respectively, after thermally equilibrating the rotor at $6^{\circ} \mathrm{C}$. Data analysis was performed with the software provided by Allen P. Minton (NIDDK, NIH).

Gel filtration. A Superose 12 column (Amersham) attached to the Akta Purifier system (Amersham) was equilibrated and calibrated in $20 \mathrm{mM}$ Tris/ $\mathrm{HCl}, \mathrm{pH} 7.5,150 \mathrm{mM} \mathrm{NaCl}, 2 \mathrm{mM}$ EGTA or $0.2 \mathrm{mM} \mathrm{CaCl}_{2}$, at a $0.3 \mathrm{ml} / \mathrm{min}$ flow. Low Molecular Weight Gel Filtration Calibration Kit (Amersham) was used for a broad calibration range and next precise calibration within 20-60 kDa was performed using purified globular proteins of known structure: UbcH5a (17 kDa), staphopain B (20 kDa), murein endopeptidase $(28 \mathrm{kDa})$, prostaphopain B $(40 \mathrm{kDa})$, and BSA (60 kDa). Protein samples were applied in max. $100 \mu \mathrm{l}$ volume at $2.2 \mathrm{mg} / \mathrm{ml}$. Calmyrin samples were loaded on this column and analyzed under the same conditions, protein peaks were collected and elution of reduced $(-\mathrm{SH})$ or $\mathrm{S}-\mathrm{S}$ calmyrin was confirmed by $12 \%$ SDS/PAGE under non reducing conditions. $K_{\text {av }}$ $=\mathrm{Ve}-\mathrm{Vo} / \mathrm{Vt}-\mathrm{Vo}$ values were calculated using $\mathrm{Vo}$ and $\mathrm{Vt}$ provided by the column manufacturer.

Cell culture and fractionation. Human lymphocytes were immortalized using Epstein-Barr virus as described earlier (Miller, 1974) and grown in RPMI supplemented with 10\% FBS. Lymphocytes and human platelets were homogenized in $50 \mathrm{mM}$ Mes, $5 \mathrm{mM} \mathrm{CaCl}_{2}$ or $2 \mathrm{mM}$ EGTA, $5 \mathrm{mM} \mathrm{MgCl}$, 150 $\mathrm{mM} \mathrm{NaCl}$, and protease inhibitor cocktail (Roche) with a Dounce (teflon-glass) homogenizer and centrifuged at $1000 \times g$ for $15 \mathrm{~min}$ at $4^{\circ} \mathrm{C}$ to pellet cell nuclei/debris. The supernatant was used for Western blotting with antibodies (see below) against calmyrin. Part of the lymphocyte supernatant was centrifuged again at $100000 \times g$ for $1 \mathrm{~h}$ at $4^{\circ} \mathrm{C}$. The pellet containing crude lymphocyte membrane fraction was solubilized in 3\% Triton X-100. After $30 \mathrm{~min}$ of incubation at $4^{\circ} \mathrm{C}$, the fraction was centrifuged at 11000 $\times g$ for $30 \mathrm{~min}$, and the supernatant was taken for a cross-linking experiment. Crude membrane fraction of rat brain (pellet after $100000 \times g$ ) was prepared similarly as of human lymphocytes and was next analyzed by Western blotting.

Crosslinking and Western blotting. $7 \mu \mathrm{g}$ of purified recombinant calmyrin in PBS or $30 \mu \mathrm{g}$ of solubilized membrane fraction with or without addition of $100 \mathrm{ng}$ of purified calmyrin were incubated in $0.1 \mathrm{mM} \mathrm{CaCl}_{2}$ or $2 \mathrm{mM}$ EGTA for $30 \mathrm{~min}$ at $4^{\circ} \mathrm{C}$. After this incubation BS3 (bis-(sulfosuccinimidyl)suberate, Pierce) was added to $4 \mathrm{mM}$ final concentration and the reaction mixture was incubated for $30 \mathrm{~min}$ at room temperature. The reaction was quenched by addition of a buffer containing Tris. Cellular protein fractions were separated on $12 \%$ SDS/PAGE gels, blotted onto nitrocellulose, blocked with $5 \%$ non-fat dry milk and incubated overnight with anti-calmyrin polyclonal antibodies diluted 1:20000. These antibodies were generated (Innovagen, Sweden) against our purified recombinant human calmyrin protein and their specificity was initially confirmed by immunoblotting of the recombinant protein. Detection was performed with HRP-conjugated anti-rabbit secondary antibody (Sigma) and the ECL detection kit (Amersham Biosciences).

\section{RESULTS}

\section{Calmyrin covalent dimers are stable in vitro and change conformation in response to increased $\mathrm{Ca}^{2+}$ concentration}

Human calmyrin contains three cysteine residues which may participate in the formation of intra- and intermolecular disulfide bridges. To detect possible covalent oligomers, recombinant calmyrin 
purified to homogeneity was analyzed on an SDSgel under non-reducing conditions (Fig. 1). This analysis revealed that the calmyrin sample was composed of monomers and dimers. The ratio of these two calmyrin forms was similar in samples containing $0.2 \mathrm{mM} \mathrm{Ca}^{2+}$ or $2 \mathrm{mM}$ a $\mathrm{Ca}^{2+}$ chelator (EGTA), suggesting that $\mathrm{Ca}^{2+}$ concentration does not regulate calmyrin dimerization. Incubation of calmyrin for 30 min in the presence of several reducing agents of varying redox potential proved insufficient for full reduction of the disulfides stabilizing the calmyrin dimer (Fig. 1a). The dimers were fully converted to monomers only after long-term incubation at strongly reducing conditions (Fig. 1b), what suggested that calmyrin dimerization occurred by formation of stable intermolecular disulfide bridges. Again, no significant changes in susceptibility of the covalent dimers to reducing agents were observed comparing calmyrin samples containing $\mathrm{Ca}^{2+}$ or EGTA (Fig. 1). While non-reducing SDS/PAGE method allowed the detection of calmyrin covalent dimers, monomers containing intramolecular disulfide bridges were difficult to be distinguished from those containing reduced sulfhydryls.

The molecular mass of calmyrin monomer determined by non-reducing SDS/PAGE corresponded to $21.0 \mathrm{kDa}$ and that for $\mathrm{S}-\mathrm{S}$ stabilized calmyrin dimmer to $38.2 \mathrm{kDa}$. Since SDS can denature noncovalent calmyrin oligomers, we applied analytical ultracentrifugation and gel filtration to determine

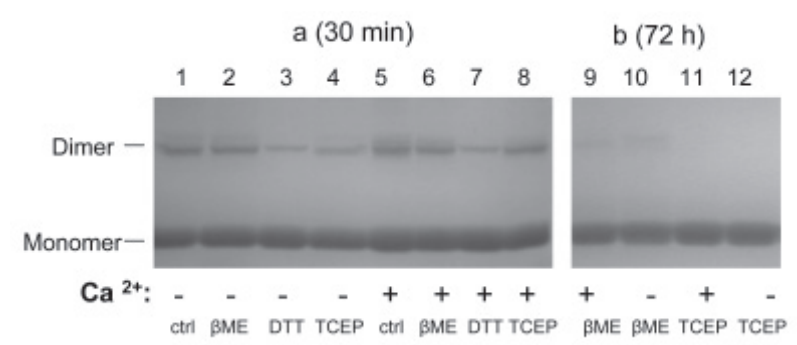

Figure 1. Calmyrin forms stable intermolecular disulfide bridges in the presence or absence of $\mathrm{Ca}^{2+}$.

Non-reducing $12 \%$ SDS/PAGE of purified calmyrin in 2 mM EGTA $(1-4,10,12)$ or in $0.1 \mathrm{mM} \mathrm{CaCl}_{2}(5-8,9,11)$ before $(1,5)$ and after incubation at $4^{\circ} \mathrm{C}$ for: a) $30 \mathrm{~min}$, b) $72 \mathrm{~h}$ with reducing agents: $2 \mathrm{mM} 2-\mathrm{ME}(2,6), 30 \mathrm{mM}$ DTT $(3,7), 20 \mathrm{mM}$ 2-ME $(9,10)$ and $2 \mathrm{mM}$ TCEP $(4,8$, $11,12)$.

the molecular mass of recombinant calmyrin forms. The ultracentrifugation results obtained for sedimentation equilibrium at 42000 r.p.m. at a $220 \mu \mathrm{M}$ initial protein concentration allowed detection of apo-calmyrin monomers with the molecular mass of 21.9 $\mathrm{kDa}$ (Fig. 2A, a). This value is similar to the molecular mass of $23.6 \mathrm{kDa}$ determined by Gentry et al. (2004), and close to the predicted $21.7 \mathrm{kDa}$. The high rotational speeds required by the meniscus depletion method prevented detection of oligomers under these conditions. To enable detection of calmyrin oligomers, sedimentation equilibrium at 18000 r.p.m.
A

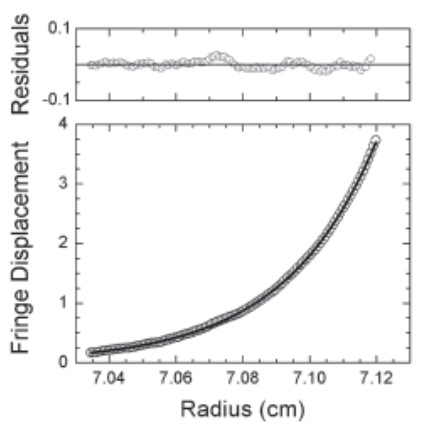

B b

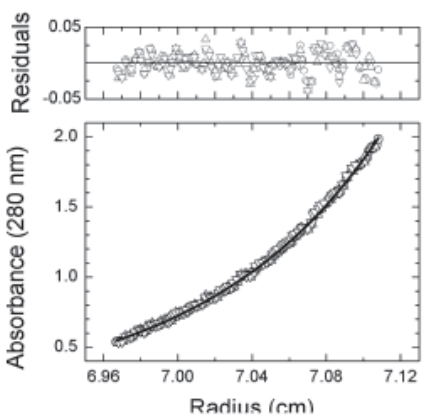

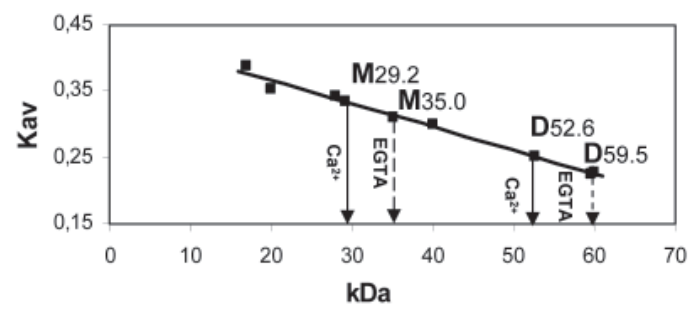

Figure 2. Calmyrin exists as monomer and covalent dimer in vitro and both forms change conformation in response to $\mathrm{Ca}^{2+}$.

A. Sedimentation equilibrium of calmyrin analyzed at $6^{\circ} \mathrm{C}$ at: a) 42000 r.p.m. for $26 \mathrm{~h}$ and (b) 18000 r.p.m. for 75 h. Molecular mass values were determined based on absorbance scans as described in Materials and Methods. Ultracentrifuged calmyrin in $20 \mathrm{mM}$ Tris/ $\mathrm{HCl}, 150 \mathrm{mM} \mathrm{NaCl}, 1 \mathrm{mM}$ EGTA, $2 \mathrm{mM}$ 2-ME, pH 7.5, was also analyzed by $12 \%$ non-reducing SDS/PAGE (c). B. Gel filtration on Superose 12 column. Linear regression fit $\mathrm{R}^{2}=0.9831$. M, monomer; D, dimer. 
was performed and the data were analyzed using a global fit of three scans taken in 30 min intervals. A representative sedimentation equilibrium absorbance scan for calmyrin after $26 \mathrm{~h}$ at 18000 r.p.m. is shown in Fig. 2B, b, together with the fit of this data to a model of reversible self-association of a monomer to a dimer. Residuals of the fit showed random distribution around zero with less than 0.03 absorbance deviations. The calculated dimerization constant is $K_{A}{ }^{\mathrm{N}}=1.78 \times 10^{3} \mathrm{M}^{-1}$ at $6^{\circ} \mathrm{C}$. Trimeric or tetrameric species were not detected. Under these conditions, approx. $40 \%$ of the protein was present in the form of a $43.8 \mathrm{kDa}$ dimer. A similar dimer content (31\%) was determined in a sample subjected to ultracentrifugation at 18000 r.p.m. by densitometry of calmyrin forms separated in non-reducing SDS-gels (Fig. 2A, c). This suggests that calmyrin exists in vitro in an equilibrium of monomers and dimers stabilized by disulfide bridges. Formation of intramolecular sulfhydryl bonds cannot be excluded.

We further analyzed the forms of recombinant calmyrin by gel filtration under non-reducing conditions in the presence or absence of $\mathrm{Ca}^{2+}$ (Fig. 2B). Under both conditions two protein peaks were observed in the elution profiles. The protein peak identified by non-reducing SDS/PAGE as a monomer was eluted at a volume corresponding to $29.2 \mathrm{kDa}$ in $\mathrm{Ca}^{2+}$ presence and to $35.0 \mathrm{kDa}$ in EGTA presence (Fig. 2B). These molecular mass values of calmyrin monomer in the presence or absence of $\mathrm{Ca}^{2+}$ are sim-

\section{A}

B
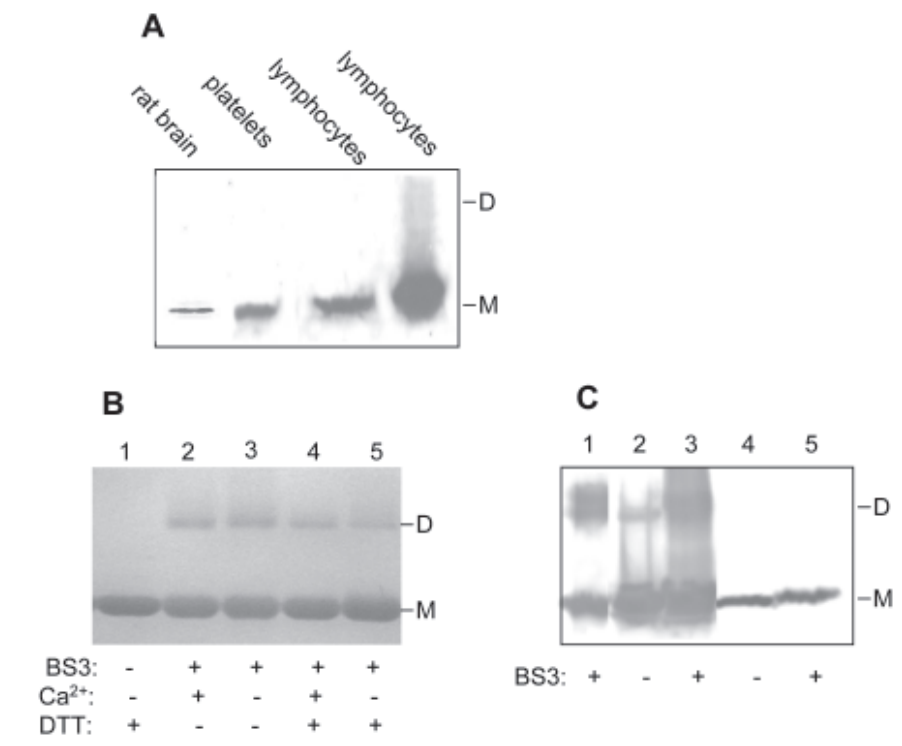

ilar to the results published earlier $\left(30.6 \mathrm{kDa} \mathrm{Ca}{ }^{2+}\right.$ monomer, $32.5 \mathrm{kDa}$ apo-monomer) (Gentry et al., 2004). These values are higher than those predicted by amino-acid sequence or ones determined by analytical ultracentrifugation, but gel filtration may reflect the shape difference between the dumbbell-like EF-hand protein and the typical globular proteins used for calibration of gel filtration columns. Some other EF-hand proteins also elute from size exclusion chromatography resins at volumes corresponding to a higher than predicted molecular mass (e.g. Olshevskaya et al., 1999). We also observed a difference in the molecular mass of apo- and $\mathrm{Ca}^{2+}$-bound calmyrin monomer, in agreement with NMR data showing a conformational change in calmyrin into a more compact structure caused by $\mathrm{Ca}^{2+}$ binding (Yamniuk et al., 2004). Our gel filtration data demonstrated separation of calmyrin monomers from dimers stabilized by S-S bridges (Fig. 2B). The protein peak containing calmyrin dimers eluted at a volume corresponding to $52.6 \mathrm{kDa}$ in $\mathrm{Ca}^{2+}$ presence, and to $59.5 \mathrm{kDa}$ in EGTA presence. The molecular mass values were slightly less than double of those determined for calmyrin monomers, which seems to reflect a more compact conformation of apo- and $\mathrm{Ca}^{2+}$-dimers compared to monomers. Importantly, the difference in the apparent molecular masses of dimers under different $\mathrm{Ca}^{2+}$ concentrations points to a significant conformational change in dimers upon $\mathrm{Ca}^{2+}$ binding (Fig. 2B). It suggests that both calmyrin

Figure 3. Calmyrin in cell extracts exists only in monomeric form.

A. Western blot developed with anti-calmyrin antibodies of protein fractions maintained at non-reducing conditions: Lines from the left: (1) rat brain solubilized membranes, (2-4) human cell extracts after removal of cell debris/nuclei by centrifugation at $1000 \times \mathrm{g}$. Equal amounts of protein $(30 \mu \mathrm{g})$ were loaded in lanes $1-3$ and $60 \mu \mathrm{g}$ in lane 4 . B. 12\% SDS/ PAGE analysis of : (1) recombinant calmyrin, (2-5) calmyrin crosslinked with BS3 in the absence $(2,3)$ or presence $(4,5)$ of $2 \mathrm{mM}$ DTT and $0.1 \mathrm{mM} \mathrm{CaCl}_{2}(2,4)$ or $2 \mathrm{mM}$ EGTA $(3,5)$. Equal amounts of protein $(7 \mu \mathrm{g})$ were loaded in each lane. C. Western blot developed with anti-calmyrin antibodies (1) $50 \mathrm{ng}$ of purified recombinant calmyrin crosslinked with BS3, (2-5) solubilized lymphocyte membranes: $(2,3)$ containing $100 \mathrm{ng}$ of added recombinant calmyrin, $(4,5)$ no exogenous calmyrin, $(2,4)$ before, and $(3,5)$ after crosslinking with BS3. Equal amounts of membrane proteins $(30 \mu \mathrm{g})$ were loaded in each lane. $\mathrm{M}$, monomer, $\mathrm{D}$, dimer. 
monomers and covalent dimers are able to bind $\mathrm{Ca}^{2+}$ and change their conformation. Therefore, it seems possible that calmyrin dimers may function in $\mathrm{Ca}^{2+}$ signalling to target molecules in cells.

Calmyrin in cell extracts does not form dimers and is present only as a monomer

We aimed at verification of the hypothesis that covalent dimers may represent the $\mathrm{Ca}^{2+}$-sensing calmyrin form in vivo. We earlier found that calmyrin protein levels are rather low in human brain, even in membrane fractions where calmyrin was enriched (Bernstein et al., 2005). Therefore, in this report we investigated the forms of endogenous calmyrin in rat brain membranes as well as in cell extracts from human lymphocytes and platelets, which contain higher amounts of calmyrin (Fig. 3A). Immunoblotting of cell extracts maintained under non-reducing conditions demonstrated the presence of calmyrin monomers and a lack of dimeric species in neuronal and non-neuronal cells (Fig. 3A). Even doubling the protein amount in the lymphocyte extract did not allow detection of calmyrin dimers, while monomer immunoreactivity was very strong (Fig. 3A).

We decided to aid the preservation of possible dimeric species in the extracts by crosslinking them before analysis. As visualized by SDS/PAGE in Fig. $3 \mathrm{~B}$, dimers formed by recombinant calmyrin in vitro can be efficiently crosslinked even in the presence of reducing agents and irrespective of $\mathrm{Ca}^{2+}$ concentration. This data confirmed our previous observations that calmyrin dimers are stable, relatively resistant to reduction, and that they are formed by calmyrin in the apo- or $\mathrm{Ca}^{2+}$-bound state. Similar results were obtained when the crosslinking was performed in lymphocyte extracts containing exogenous calmyrin (Fig. 3C), proving that crosslinker concentration under the applied conditions was sufficient for preservation of dimers formed by the exogenous protein. However, no dimers were detected after crosslinking of cell extracts without exogenous calmyrin, confirming the lack of endogenous dimeric calmyrin forms in the cell extracts. The only detected calmyrin form in vivo was the monomeric one when either 2 mM EGTA or $0.2 \mathrm{mM} \mathrm{Ca}^{2+}$ were added to the cell extracts (not shown).

\section{DISCUSSION}

Multiple studies evidenced that most EF-hand proteins from the S100 family exhibit biological activity not as monomers, but as homo- or heterodimers (Wojda \& Kuznicki, 1994; Donato, 2001; Maler et al., 2002; Moroz et al., 2003; Koltzscher et al, 2003), and proved that the mechanism of dimer formation is also functionally relevant. For instance, S100B ex- hibits the activity of neurite extension factor only as a covalent dimer stabilized by disulfide bridges (Winningham-Major et al., 1989; Haglid et al., 1997), while a non-covalent homodimer represents physiological form of S100A6, despite the ability of S100A6 to form disulfide-bound dimers (Wojda \& Kuznicki, 1993; 1994; Potts et al., 1995). Posttranslational maturation of proteins includes formation of disulfide bridges where it is required for stability and function, while reduced sulfhydryls are maintained in proteins designed to function without intermolecular covalent bonds (Wendland et al., 1991). While the S100 proteins in the apo- and $\mathrm{Ca}^{2+}$-bound state exist as dimers, some EF-hand NCS proteins exhibit $\mathrm{Ca}^{2+}$-dependent dimerization or oligomerization (Vijay-Kumar \& Kumar, 1999; Olshevskaya et al., 1999; Osawa et al., 2001; Zhou et al., 2004). Recently, an NCS homolog, the EF-hand-type $\mathrm{Ca}^{2+}$-binding recombinant calmyrin was shown to exist under reducing conditions mainly in the monomeric state, with some marginal ability to dimerize (Gentry et al., 2004). Here we demonstrated that calmyrin can dimerize in vitro via disulfide bridges and that this dimerization is not $\mathrm{Ca}^{2+}$-dependent. Both in the presence and absence of $\mathrm{Ca}^{2+}$ calmyrin can exist in an equilibrium of monomers and dimers undergoing reversible self-association. Moreover, our data show that although calmyrin forms dimers irrespective of $\mathrm{Ca}^{2+}$-binding, covalent dimers change conformation in response to increasing $\mathrm{Ca}^{2+}$ concentrations. This suggests that, at least in theory, dimers may independently function in $\mathrm{Ca}^{2+}$-signalling in vivo and may potentially transduce $\mathrm{Ca}^{2+}$ signals to different protein targets than monomers. Accordingly, the cysteine residues in calmyrin seem to be conserved in mammals. However, no covalent dimers were detected under non-reducing conditions in rat brain membrane preparations and in human lymphocytes and platelets, where calmyrin is highly expressed. Also, no covalent or non-covalent calmyrin dimers were preserved by crosslinking in cell extracts, implicating maintenance of calmyrin in the monomeric conformation in the cell in vivo.

Homology-based models of calmyrin assumed $\mathrm{Ca}^{2+}$-dependent exposure of hydrophobic residues in the C-terminal domain of calmyrin (Hwang \& Vogel, 2000). Such exposure is typical for calmodulin and other calcium sensor proteins enabling subsequent binding to $\alpha$-helical structures of their cellular targets. Indeed, a hydrophobic pocket has been described in the crystal structure of calmyrin molecule on the opposite side from EF-hands 3 and 4 in the C-terminal part of the protein (Gentry et al., 2004). The above mechanism of $\mathrm{Ca}^{2+}$ signalling seems to be involved in calmyrin binding to the $\alpha$-helical cytoplasmic tail of platelet integrin $\alpha \mathrm{II} \beta 3$ (Barry et al., 2002). However, the broad spectrum of calmyrin protein targets ranging from the nuclear DNA-de- 
pendent kinase (Wu et al., 1997) to the membraneous presenilin 2 (Stabler et al., 1999) challenges the uniform mechanism of target binding. Moreover, there are also examples of EF-hand proteins which bind some targets in a $\mathrm{Ca}^{2+}$-independent manner employing acidic residues of their EF-hand structures (see for instance Atkinson et al., 2001; Seidenbecher et al., 2004). The data presented here show that calmyrin dimers or oligomers seem not to be present in cells and thus cannot account for differential target recognition and binding. Also, since calmyrin interaction with its cellular targets was originally identified in a yeast-two-hybrid screen, where the N-terminal myristoylation was not involved, a $\mathrm{Ca}^{2+}$-myristoyl switch mechanism for these interactions is hard to conceive. In this light elucidation of the structural basis for the specificity of monomeric calmyrin interactions with its various cellular targets awaits further investigations.

\section{Acknowledgements}

This work was supported by a grant from the State Committee for Scientific Research PBZ-MIN001/P05/09.

We thank Dr. Ann Ginsburg (NHLBI/NIH, Bethesda, USA) for help in ultracentrifugation studies and Dr. Mathias Bochtler's group (IIMCB, Warsaw, Poland) for providing proteins used for calibration of Superose 12.

\section{REFERENCES}

Ames JB, Ishima R, Tanaka T, Gordon JI, Stryer L, Ikura M (1997) Molecular mechanics of calcium-myristoyl switches. Nature 389: 198-202.

Atkinson RA, Joseph C, Kelly G, Muskett FW, Frenkiel TA, Nietlispach D, Pastore A (2001) $\mathrm{Ca}^{2+}$-independent binding of an EF-hand domain to a novel motif in the alpha-actinin-titin complex. Nat Struct Biol 8: 853-857.

Barry WT, Boudignon-Proudhon C, Shock DD, McFadden A, Weiss JM, Sondek J, Parise LV (2002) Molecular basis of CIB binding to the integrin IIb cytoplasmic domain. J Biol Chem 277: 28877-28883.

Bernstein HG, Blazejczyk M, Rudka T, Gundelfinger ED, Dobrowolny H, Bogerts B, Kreutz MR, Kuznicki J, Wojda U (2005) The Alzheimer disease-related calcium-binding protein Calmyrin is present in human forebrain with an altered distribution in Alzheimer's as compared to normal aging brains. Neurpathol Appl Neurosci 31: 314-324.

Berridge MJ (1998) Neuronal calcium signaling. Neuron 21: 13-26.

Burgoyne RD, Weiss JL (2001) The neuronal calcium sensor family of $\mathrm{Ca}^{2+}$-binding proteins. Biochem J 353: 1-12.

Donato R (2001) S100: a multigenic family of calcium-modulated proteins of the EF-hand type with intracellular functional roles. Int J Biochem Cell Biol 33: 637-668.

Gentry HR, Singer AU, Betts L, Yang C, Ferrara JD, Sondek J, Parise LV (2005) Structural and biochemical characterization of CIB1 delineates a new family of EF-hand containing proteins. J Biol Chem 280: 8407-8415.
Fang X, Chen C, Wang Q, Gu J, Chi C (2001) The interaction of the calcium- and integrin-binding protein (CIBP) with the coagulation factor VIII. Thromb Res 102: $177-185$.

Haglid KG, Yang Q, Hamberger A, Berman S, Widerberg A, Danielsen N (1997) S100beta stimulates neurite outgrowth in the rat sciatic grafted with acellular nuscle transplants. Brain Res 753: 196-201.

Heizmann CW, Hunziker W (1991) Intracellular calciumbinding proteins: more sites than insights. Trends Biochem Sci 16: 98-103.

Henderson MJ, Russell AJ, Hird S, Munoz M, Clancy JL, Lehrbach GM, Calanni ST, Jans DA, Sutherland RL, Watts CK (2002) EDD, the human hyperplastic discs protein, has a role in progesterone receptor coactivation and potential involvement in DNA damage response. J Biol Chem 277: 26468-26478.

Hollenbach AD, McPherson CJ, Lagutina I, Grosveld G (2002) The EF-hand calcium-binding protein calmyrin inhibits the transcriptional and DNA-binding activity of Pax3. Biochim Biophys Acta 1574: 321-328.

Hwang PM, Vogel HJ (2000) Structures of the platelet calcium- and integrin-binding protein and the alphallbintegrin cytoplasmic domain suggest a mechanism for calcium regulated recognition; homology modelling and NMR studies. J Mol Recog 13: 83-92.

Ikura M (1996) Calcium binding and conformational response in EF-hand proteins. Trends Biochem Sci 21: 14-17.

Ito A, Uehara T, Nomura Y (2000) Isolation of Ich-1S (caspase-2S)-binding protein that partially inhibits caspase activity. FEBS Lett 470: 360-364.

Kauselmann G, Weiler M, Wulff P, Jessberger S, Konietzko U, Scafidi J et al. (1999) The polo-like protein kinases Fnk and Snk associate with $\mathrm{Ca}^{2+}$ - and integrin-binding protein and are regulated dynamically with synaptic plasticity. $E M B O J$ 18: 5528-5539.

Koltzscher M, Neumann C, Konig S, Gerke V (2003) $\mathrm{Ca}^{2+}$ dependent binding and activation of dormant ezrin by dimeric S100P. Mol Biol Cell 14: 2372-2384.

Lee GE, Yu EY, Cho CH, Lee J, Muller MT, Chung IK (2004) DNA-protein kinase catalytic subunit-interacting protein KIP binds telomerase by interacting with human telomerase reverse transcriptase. J Biol Chem 279: 34750-34755.

Ma S, Liu MA, Yuan YL, Erikson RL (2003) The seruminducible protein kinase Snk is a G1 phase polo-like kinase that is inhibited by the calcium- and integrinbinding protein CIB. Mol Cancer Res 1: 376-384.

Maler L, Sastry M, Chazin WJ (2002) A structural basis for S100 protein specificity derived from comparative analysis of apo and $\mathrm{Ca}(2+)$-calcyclin. J Mol Biol 317: 279-290.

Meyer T, York JD (1999) Calcium-myristoyl switches turn on new lights. Nat Cell Biol 1: 93-95.

Miller G (1974) The oncogenicity of Epstein-Barr virus. J Infect Dis 130: 187-205.

Moroz OV, Dodson GG, Wilson KS, Lukanidin E, Bronstein IB (2003) Structural states of S100A12: A key to its functional diversity. Microsc Res Tech 60: 581-592.

Nakayama S, Kretsinger RH (1994) Evolution of the EFhand family of proteins. Annu Rev Biophys Biomol Struct 23: 473-507.

Naik MU, Naik UP (2003) Calcium- and integrin-binding protein regulates focal adhesion kinase activity during platelet spreading on immobilized fibrinogen. Blood 102: 3629-3636.

Naik UP, Patel PM, Parise LV (1997) Identification of a novel calcium-binding protein that interacts with the 
integrin alphaIIb cytoplasmic domain. I Biol Chem 272: $4651-4654$

Nosworthy NJ, Peterkofsky A, König S, Seok Y-J, Szczepanowski RH, Ginsburg A (1998) Phosphorylation destabilizes the amino-terminal domain of enzyme I of the Escherichia coli phosphoenolpyruvate:sugar phosphotransferase system. Biochemistry 37: 6718-6726.

Olshevskaya EV, Ermilov AN, Dizhoor AM (1999) Dimerization of guanylyl cyclase-activating protein and a mechanism of photoreceptor guanylyl cyclase activation. J Biol Chem 274: 25583-25587.

Osawa M, Tong KI, Lilliehook C, Wasco W, Buxbaum JD, Cheng HY, Penninger JM, Ikura M, Ames JB (2001) Calcium-regulated DNA binding and oligomerization of the neuronal calcium-sensing protein, calsenilin/ DREAM/KChIP3. J Biol Chem 276: 41005-41013.

Potts BC, Smith J, Akke M, Macke TJ, Okazaki K, Hidaka H, Case DA, Chazin WJ (1995) The structure of calcyclin reveals a novel homodimeric fold for S100 Ca(2+)binding proteins. Nat Struct Biol 2: 790-796.

Seidenbecher CI, Landwehr M, Smalla KH, Kreutz M, Dieterich DC, Zuschratter W, Reissner C, Hammarback JA, Bockers TM, Gundelfinger ED, Kreutz MR (2004) Caldendrin but not calmodulin binds to light chain 3 of MAP1A/B: an association with the microtubule cytoskeleton highlighting exclusive binding partners for neuronal $\mathrm{Ca}^{2+}$-sensor proteins. J Mol Biol 336: 957-970.

Shock DD, Naik UP, Brittain JE, Alahari SK, Sondek J, Parise LV (1999) Calcium-dependent properties of CIB binding to the integrin alphaIIb cytoplasmic domain and translocation to the platelet cytoskeleton. Biochem I 342: 729-735.

Stabler SM, Ostrowski LL, Janicki SM, Monteiro MJ (1999) A myristoylated calcium-binding protein that preferentially interacts with the Alzheimer's disease presenilin 2 protein. I Cell Biol 145: 1277-1292.

Vijay-Kumar S, Kumar VD (1999) Crystal structure of recombinant bovine neurocalcin. Nat Struct Biol 6: 80-88.
Wendland M, von Figura K, Pohlmann R (1991) Mutational analysis of disulfide bridges in the $M_{r} 46,000$ mannose 6-phosphate receptor. Localization and role for ligand binding. J Biol Chem 266: 7132-7136.

Winnigham-Major F, Staecker JL, Barger SW, Coats S, Van Eldik LJ (1989) Neurite extension and neuronal survival activities of recombinant S100 beta proteins that differ in the content and position of cysteine residues. J Cell Biol 109: 3063-3071.

Wojda U, Kuznicki J (1993a) Biochemical properties of calcyclin - a potential marker of some diseases. Acta Biochim Polon 40: 171-175.

Wojda U, Kuznicki J (1993b) Characterization of calcyclin fragments obtained by CNBr-cleavage. Int J Biochem 25: 999-1007.

Wojda U, Kuznicki J (1994) Calcyclin from mouse Ehrlich ascites tumour cells and rabbit lung form non-covalent dimers. Biochim Biophys Acta 209: 248-252.

Wu X, Lieber MR (1997) Interaction between DNA-dependent protein kinase and a novel protein, KIP. Mutat Res 385: 13-20.

Whitehouse C, Chambers J, Howe K, Cobourne M, Sharpe P, Solomon E (2002) NBR1 interacts with fasciculation and elongation protein zeta-1 (FEZ1) and calcium and integrin binding protein (CIB) and shows developmentally restricted expression in the neural tube. Eur J Biochem 269: 538-545.

Yamniuk AP, Nguyen LT, Hoang TT, Vogel HJ (2004) Metal ion binding properties and conformational states of calcium- and integrin-binding protein. Biochemistry 43: 2558-2568.

Zamyatnin AA (1984) Amino acid, peptide and protein volume in solution. Annu Rev Biophys Bioeng 13: 145165.

Zhou W, Qian Y, Kunjilwar K, Pfaffinger PJ, Choe S (2004) Structural insights into the functional interaction of KChIP1 with Shal-type K(+) channels. Neuron 41: 573586. 